Int. J. Odontostomat.,

13(4):497-503, 2019.

\title{
L-PRF y Ciclo Celular. Revisión Narrativa
}

\author{
L-PRF and cell cycle. Narrative Review
}

\author{
Correa Aravena J.1,2,3; Alister J. P. 1; Olate S. ${ }^{1,4}$ \& Manterola C. ${ }^{1,4,5}$
}

CORREA, A. J.; ALISTER, J. P.; OLATE, S. \& MANTEROLA, C. L-PRF y Ciclo celular. Revisión narrativa. Int. J. Odontostomat., 13(4):497-503, 2019.

RESUMEN: Los concentrados plaquetarios han emergido como un potencial material regenerativo, utilizado de forma aislada o como andamiaje para otros materiales de injerto. Son extractos de sangre, obtenidos después de procesar una muestra de sangre completa, mediante centrifugación. El primer reporte data de 1970, con un CP utilizado como pegamento para mejorar cicatrización de heridas de piel. En 1998, se usaron en cirugía oral y maxilofacial. Desde entonces, se han desarrollado diferentes técnicas y una variedad de preparaciones. Entre ellas, cabe destacar el plasma rico en plaquetas, fibrina rica en plaquetas y leucocitos (L-PRF) y plasma rico en factores de crecimiento (PRGF). El desarrollo de estos biomateriales, se debe en parte, a la posibilidad de alterar la concentración de mediadores químicos liberados en una lesión que provoque la formación de un coágulo, que pueda madurar conforme transcurran las fases del proceso inflamatorio y concluya con la regeneración íntegra del tejido dañado. El objetivo de este manuscrito fue describir las principales vías de señalización intracelular que se activan en presencia del L-PRF en cirugía oral, y sus efectos en la regulación del ciclo celular.

PALABRAS CLAVE: factores de crecimiento; receptores de citoquinas; agentes angiogénicos moduladores; periodoncia; endodoncia regenerativa; plaquetas ricas en fibrina; medicina regenerativa.

\section{INTRODUCCIÓN}

La respuesta ideal de cualquier tejido ante una lesión que provoque pérdida de su integridad es la formación de un coágulo que madure conforme transcurren las fases del proceso inflamatorio y concluya con la regeneración íntegra del tejido dañado. Para lo anterior es vital que las células endoteliales vecinas pueblen rápidamente el coágulo original en cantidad suficiente para asegurar un óptimo aporte de oxígeno, nutrientes y factores de crecimiento para el reclutamiento o diferenciación a las líneas celulares del tejido original, fibroblastos u osteoblastos principalmente en cirugía oral (Martínez et al., 2015).

La quimiotaxis es el proceso mediante el cuál las células migran en función de un gradiente de concentración de mediadores químicos liberados en el sitio afectado. Esta concentración es posible alterarla para nuestro beneficio gracias al desarrollo de variados biomateriales como por ejemplo: proteínas morfogenéticas óseas (BMPs), proteínas del esmalte, fibrina rica en plaquetas y leucocitos (L-PRF) (Susin \& Wikesjö, 2013).

Numerosos son los reportes de las propiedades reparativas y regenerativas del L-PRF tanto invitro como in-vivo, pero reducida es la información disponible respecto de las vías intracelulares de señalización que llevan a la célula endotelial a proliferar de manera aumentada en presencia de concentrados plaquetarios versus controles con concentraciones habituales.

El objetivo de este manuscrito fue describir las principales vías de señalización intracelular que se activan en presencia del L-PRF en cirugía oral, y sus efectos en la regulación del ciclo celular.

\footnotetext{
${ }^{1}$ Programa de Doctorado en Ciencias Médicas, Universidad de La Frontera, Temuco, Chile.

${ }^{2}$ Universidad San Sebastián, Facultad de Odontología, Sede Patagonia, Chile.

${ }^{3}$ Hospital Dr. Eduardo Schütz Schroeder, Puerto Montt, Chile.

${ }^{4}$ Centro de Excelencia en Estudios Morfológicos y Quirúrgicos (CEMyQ), Universidad de La Frontera, Chile.

${ }^{5}$ Departamento de Cirugía y Traumatología, Universidad de La Frontera, Temuco, Chile.
} 


\section{APLICACIONES CLÍNICAS DE LOS CONCENTRA- DOS PLAQUETARIOS}

Numerosos son los usos clínicos descritos en la abultada literatura disponible actualmente para los concentrados plaquetarios, siendo quizás la reconstrucción de rebordes alveolares atróficos (Fig. 1) como preparación previa a la instalación de implantes óseo integrados su principal indicación (Castro et al., 2019).

Del mismo modo encontramos evidencia del efecto de estos biomateriales en cirugía apical (Pinto et al., 2017), a nivel de defectos infraóseos, compromisos de furcación en dientes multirradiculares, cirugía plástica periodontal y elevación de seno maxilar (Castro et al., 2017a,b) (Fig. 2), entre otras aplicaciones en el territorio bucomaxilofacial.
Concentrados plaquetarios y su composición. El uso de productos derivados de la sangre para sellar heridas y/o estimular la cicatrización comenzó con los adhesivos de fibrina hace 40 años aproximadamente y estaban constituidos por fibrinógeno concentrado y cuya polimerización era inducida por trombina y calcio. Actualmente existen productos como el Tisseel ${ }^{\circledR}$ (Baxter, USA) adhesivo de fibrina de uso tópico aprobado por la FDA para uso en cirugía general. Del mismo modo, los concentrados plaquetarios (CC) se han estudiado extensamente en las última décadas. Las plaquetas, en sus gránulos alfa, contienen altas concentraciones de factores de crecimiento (Hotwani \& Sharma, 2014) (Tabla I), como el factor de crecimiento vascular endotelial (VEGF), el factor de crecimiento transforman beta-1 (TGFß-1), el factor de crecimiento derivado de plaquetas AB (PDGF-AB) los cuales son capaces de estimular la

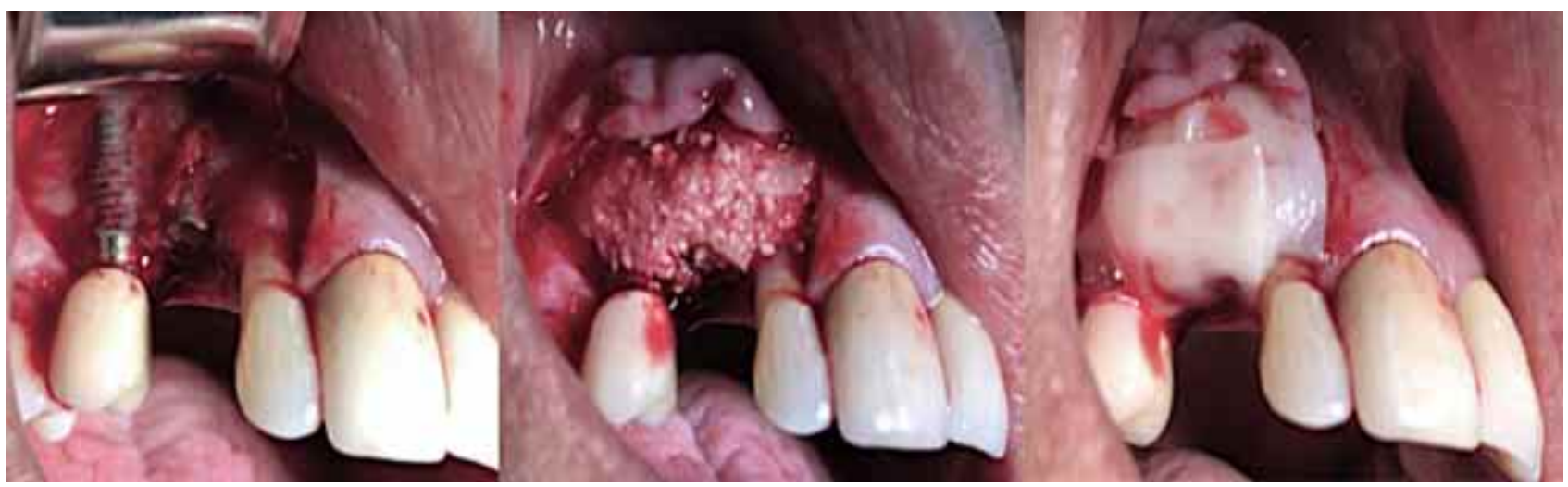

Fig. 1. Utilización de L-PRF en un caso de regeneración ósea, paralelo a la instalación de un implante oesointegrado en el diente 1.3. Se aprecia ausencia de pared vestibular en implante posición 1.4, que fue instalado con anterioridad. Se utilizaron sticky bone y membranas de L-PRF.

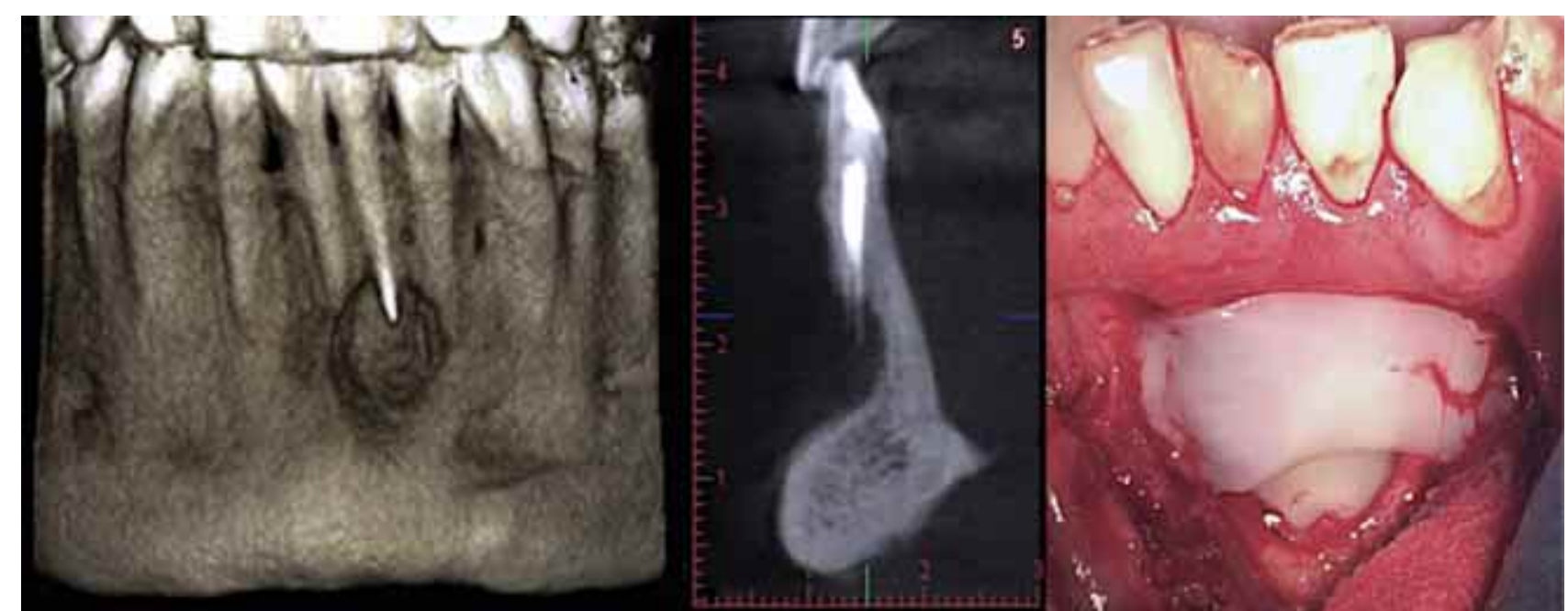

Fig. 2. Lesión apical persistente de 3 años de evolución. Una vez eliminado el tejido de granulación y el trayecto fistuloso, se retroperaró el periápice con ultrasonido y obturó con biocerámico. El defecto fue posteriormente rellenado con membranas de L-PRF. 
proliferación celular, el remodelado de la matriz y la angiogénesis (Kobayashi et al, 2016).

En general, se clasifican en concentrados plaquetarios de primera y segunda generación dependiendo si existe o no adición de sustancias químicas adicionales agregadas con la finalidad de manipular el proceso de coagulación. Así tenemos al plasma rico en plaquetas (PRP) como representante de la primera generación y a la fibrina rica en plaquetas y leucocitos (L-PRF) en la segunda generación. Esta última es un concentrado de sangre venosa pura sin químicos adicionales que se centrifuga por 12 minutos a $2700 \mathrm{rpm}$ inmediatamente obtenido (Choukroun et al., 2001). El coágulo de fibrina obtenido contiene aproximadamente un $95 \%$ de las plaquetas y un 50 $\%$ de los leucocitos contenidos en la muestra original (Pinto et al., 2018).

L-PRF y angiogénesis. Entendemos por angiogénesis al desarrollo de nuevos vasos sanguíneos a partir de capilares preexistentes. Este proceso incluye la degradación de la, membrana basal vascular, proliferación y migración de las células endoteliales y estructuración del lumen y formación de la red vascular. Está estrechamente regulado por diferentes tipos celulares (endotelio, células musculares lisas y células inflamatorias) y diferentes moléculas ya mencionadas, dentro de las cuales el VEGF es una de las más estudiadas y a la que nos referiremos en mayor detalle.
Numerosas son la indicaciones médicas y odontológicas del L-PRF (Castro et al., 2017a,b), siendo un denominador común a todas ellas la necesidad de mejorar el aporte de nutrientes y de oxígeno al sitio operatorio. En los procesos de injuria sobre el tejido óseo (fractura, osteotomía, inflamación) se produce una interrupción vascular que crea un gradiente hipóxico en la zona de lesión, en donde la tensión de oxígeno en el centro de la herida es más baja. In vivo, este microambiente hipóxico estimula la expresión de una variedad de moléculas sintetizadas por las células inflamatorias, los fibroblastos, las células endoteliales y los osteoblastos, jugando un rol preponderante el Factor Inducible por Hipoxia (HIF-1 $\alpha$ ), complejo proteico constitutivo que regula la normoxia para cada tejido y también regula la transcripción de múltiples genes (PDGF, eritropoyetina, transferrina, VEGF) (Aguirre Siancas, 2013). Este último juega un rol clave en la angiogénesis y recordemos es uno de las principales moléculas liberadas por el coágulo de L-PRF.

Vías de señalización para VEGF. EI VEGF, también conocido como factor de permeabilidad vascular (VPF), es un conjunto de proteínas producidas por variados tipos celulares como por ejemplo macrófagos, plaquetas, queratinocitos, células tumorales, desempeñando un rol fundamental en la formación del tejido óseo, hematopoyesis, cicatrización y angiogénesis, estimulando la supervivencia, proliferación y motilidad de la célula endotelial (Saavedra Torres et al., 2017). Es necesario mencionar el rol que cumplen las

Tabla I. Principales factores de crecimiento presentes en L-PRF y su función (adaptado de Hotwani \& Sharma, 2014).

\begin{tabular}{|c|c|}
\hline Factor & Función \\
\hline Interleuquina 1 (IL-1) & $\begin{array}{l}\text { Mediador clave en el control de la inflamación } \\
\text { Estimula linfocitos T-helper }\end{array}$ \\
\hline Interleuquina 6 (IL-6) & $\begin{array}{l}\text { Factor de diferenciación para linfocitos B } \\
\text { Activador de linfocitos } T\end{array}$ \\
\hline \multirow[t]{2}{*}{ Factor de necrosis tumoral alfa (TNF $\alpha)$} & $\begin{array}{l}\text { Estimula secreción de inmunoglobulinas } \\
\text { Activa monocitos } \\
\text { Estimula función remodeladora de fibroblastos } \\
\text { Aumenta fagocitosis y citotoxicidad de neutrófilos }\end{array}$ \\
\hline & Modula expresión de IL-1 y IL-6 \\
\hline Factor de crecimiento vascular endotelial (VEGF) & Inicia y regula angiogénesis \\
\hline Factor de crecimiento transformante beta 1 (TGF $\beta 1$ ) & $\begin{array}{l}\text { Induce síntesis masiva de colágeno y } \\
\text { fibronectina }\end{array}$ \\
\hline Factor de crecimiento derivado de plaquetas (PDGF) & $\begin{array}{l}\text { Regula migración y proliferación de líneas } \\
\text { celulares mesenquimales }\end{array}$ \\
\hline Factor de crecimiento similar a insulina 1 y 2 (IGF-1 e IGF-2) & Mediador de multiplicación celular en apoptosis \\
\hline & Quimiotáctico para osteoblastos \\
\hline
\end{tabular}


Angiopoyetinas en la modulación el efecto del VEGF. Algunos estudios han determinado la ocurrencia de dos eventos que contribuyen a la adquisición de un fenotipo angiogénico en fases iniciales de la progresión tumoral: la hipoxia y el aumento en la expresión de la angiopoyetina 1 y 2 . La angiopoyetina 1 (Ang1) es secretada por los pericitos vecinos al vaso sanguíneo y se une de manera específica al receptor Tie2 de la célula endotelial, estimulando su metabolismo. Por su parte la angiopoyetina 2 (Ang2) se une al mismo receptor, pero tiene un efecto angiogénico en presencia de VEGF y antiangiogénico en su ausencia. La activación de la vía Ang1/Tie2 por concentrados plaquetarios (PRP y L-PRF) se ha demostrado en estudios in-vitro e in-vivo (Mammoto et al., 2013).

Existen 3 tipos de receptor para el VEGF con actividad tirosin-kinasa intrínseca (VEGFR1, VEGFR2, VEGFR3) localizados en células endoteliales y otros tipos celulares EI VEGF-A regula la angiogénesis y la permeabilidad vascular mediante la activación de los receptores VEGFR1 y VEGFR2. A grandes rasgos, estos receptores cumplen su principal rol en la embriogénesis, angiogénesis y linfangiogénesis, respectivamente (Matsumoto \& Claesson-Welsh, 2001). Activan conocidas vías de señalización intracelular que podemos resumir en la Figura 3.
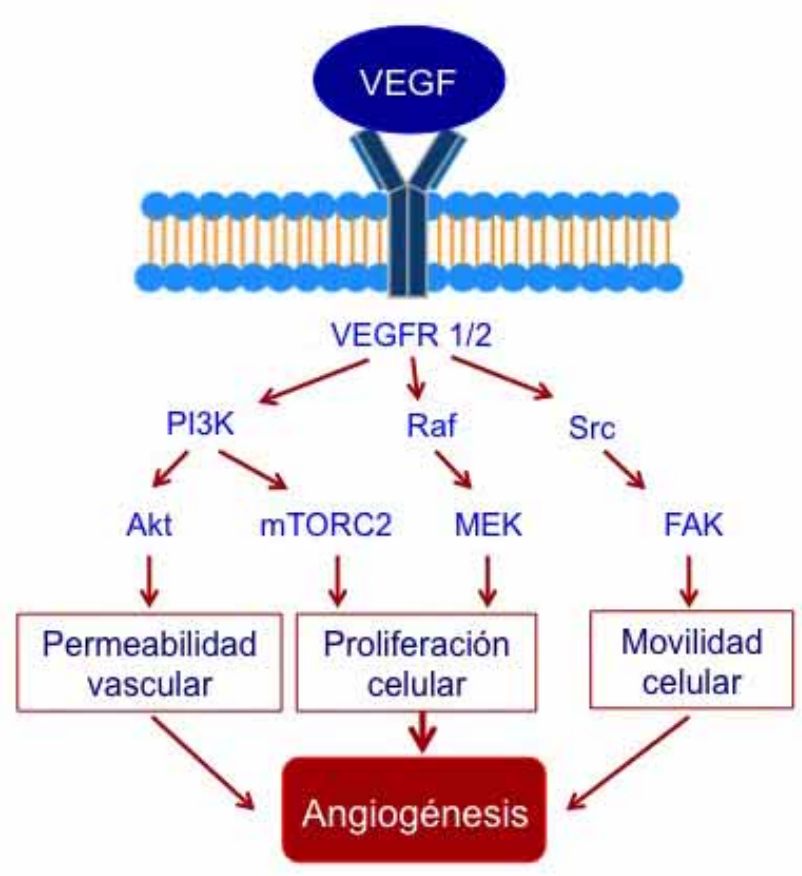

Fig. 3. Principales vías de señalización producto de la activación del receptor para VEGF. Adaptado de Guo et al. (2018).
Vía del Fosfatidil inositol 3 Kinasa (PI3K). La vía de señalización de la fosfatidilinositol3-kinasa (PI3K) es vital en aspectos celulares involucrados en el crecimiento y la supervivencia celular. La PI3K activa, fosforila el fosfatidil inositol difosfato (PIP2) convirtiéndolo en el segundo mensajero fosfatidil inositol trifosfato (PIP3), el cual, corriente abajo, conduce a la activación de la proteína Akt. Akt es el homólogo humano del oncogén viral v-Akt (retrovirus Akt 8) y está relacionado con proteínas quinasas $A(P K A)$ y $C$ (PKC). Incrementan la expresión de genes anti-apoptóticos incluyendo: CREB (proteína de unión a elementos de respuesta a AMP-cíclico) mediante fosforilación directa, NF-Kß e HIF-1a. La activación del factor de transcripción NF-Kß, a través de Akt, se genera inicialmente mediante la fosforilación y consecuente activación de IKKab (quinasa inhibidora de NF-kß), que fosforita y marca a lkß (inhibidor de NFkß) para ser degradado mediante el sistema ubiquitina-proteosoma, dejando libre a NF-kß, favoreciendo tanto su translocación al núcleo, como su actividad de transcriptor de genes antiapoptóticos. Otro efecto de Akt, para favorecer la supervivencia celular, es la inactivación del gen supresor de tumor, p53; lo cual se da por la habilidad de Akt para fosforilar y activar directamente a MDM2, una proteína que regula negativamente a p53. MDM2 se encuentra usualmente en el citoplasma y tiene dominios NSL (señalización de localización nuclear) y de unión a p53. Cuando MDM2 es activado por Akt, se transloca al núcleo para unirse a p53, impidiendo su actividad como factor de transcripción de genes proapoptóticos; posteriormente, sale nuevamente al citoplasma donde media los procesos de ubiquitinación y degradación proteosómica de p53, disminuyendo sus niveles. Cuando la vía PI3K/Akt se encuentra en un estado de activación permanente, el anterior mecanismo permite que una célula, aún en malas condiciones, resista a la apoptosis, sobreviva y prolifere.

La proteína serina/treonina kinasa, mTOR (blanco mamífero de rapamicina) activada por Akt, se puede considerar como el regulador central del crecimiento celular. Además, mTOR regula la traducción proteica, en respuesta a nutrientes y factores de crecimiento, al fosforilar componentes de la maquinaria de la síntesis de proteínas. Además existe evidencia de la activación directa de la vía mTORC2 por la PI3K (Gan et al., 2011)

Adicionalmente, la vía de PI3K/Akt interactúa con los mecanismos de control de la energía celular y el metabolismo de la glucosa. Cuando se genera estrés celular, por depleción de glucosa y/o hipoxia, aumen- 
tan los niveles de AMP y disminuyen los de ATP por falta en la producción de energía; es decir, hay una alteración en la relación AMP/ATP.

Asimismo, Akt está involucrado en los procesos de regulación del ciclo celular al fosforilar las CKI (inhibidores de quinasas dependientes de ciclinas) p21CIP1/WAF1 y p27KIP1, favoreciendo, de esta manera, su translocación al citoplasma y posterior degradación. Como resultado, se incrementa la proliferación celular, al abolirse el efecto antiproliferativo de las CKI sobre los complejos de ciclina-kinasas, y también, probablemente, a funciones citosólicas novedosas de los CKI.

En resumen, la señalización de PI3K controla la angiogénesis, el crecimiento, la proliferación, la senescencia y otros procesos, a través de mecanismos como la activación transcripcional del factor de crecimiento vascular endotelial (VEGF) y la expresión del factor 1a inductor de hipoxia (HIF-1 $\alpha$ ) (Pinzón et al., 2009; Karar \& Maity, 2011).

Vía Ras/Raf/MEK/ERK. Al igual que la mayoría de estas vías, dependiendo del estímulo y del tipo celular será el efecto generado, pudiendo ser diferenciación, prevención o inducción de apoptosis o progresión del ciclo celular. Mutaciones en los genes H-Ras, K-Ras, $\mathrm{N}$-Ras los convierten en oncogenes (Karar \& Maity). Ras es una proteína que liga GTP y es la encargada de activar esta vía. Diferentes mutaciones se han descrito en los genes Ras en pacientes con cáncer, lo que haría variar su capacidad para activar esta y otras vías. Estas ERKs (Extracellular signal Regulated Kinase) ejercen su efecto sobre una variedad de factores, como por ejemplo, AP-1, c-Myc, NF-kß, entre otros, involucrados en la expresión de importantes genes de progresión del ciclo celular (CDKs, ciclinas, factores de crecimiento) y de prevención de apoptosis (Bcl-2 y citoquinas) (Chang et al., 2003).

Vía del SRC. Esta familia de proteínas quinasa están involucradas en la permeabilidad vascular. Se sugiere que SRC juega un rol en la supervivencia de la célula endotelial regulando la actividad de PI3K. Fak (Focal Adhesion Kinase) activada recluta proteínas de anclaje a actina (como talina y vinculina) favoreciendo la migración del endotelio (Matsumoto \& ClaessonWelsh).

Ciclinas reguladoras del ciclo celular. En reparación y regeneración de tejidos, el concepto crecimiento está implícito. Aumento del número de células para que produzcan y recuperen la matriz extra celular dañada. Para que esto ocurra las células vecinas a la lesión deben proliferar en respuesta a los factores liberados, es decir, la célula debe necesariamente multiplicarse para que el tejido dañado sea capaz de responder al desafío reparativo.

La progresión del ciclo celular es activada directamente por una serie de complejos proteicos formados por las ciclinas y las kinasas dependientes de ciclina (CDKs). La decisión de una célula para entrar en fase $S$ está estrechamente controlada por el complejo ciclina D/CDK4/6 y los complejos ciclina E/CDK2, seguido del complejo ciclina A/CDK2 a lo largo de la fase S (Fig. 4). La progresión de la fase G1 a S también esta regulada por la proteína del retinoblastoma $(\mathrm{Rb})$, una proteína supresora de tumor que desempeña un papel fundamental en el control negativo de ciclo celular y en la progresión tumoral. La ciclina $\mathrm{D}$, al formar un complejo con las kinasas dependientes de ciclina CDK4 o 6, activa la acción de la quinasa cuyo sustrato principal es la proteína $\mathrm{Rb}$. En su estado hipofosforilado, la proteína Rb está activa y lleva a cabo su función mediante la inhibición de la progresión del ciclo celular, bloqueando los factores de transcripción E2F1, E2F2 y E2F3a, que son esenciales para la expresión de genes que le darán continuidad al ciclo. La progresión de la fase $\mathrm{G} 1$ en células de mamíferos está mediada por las actividades del complejo ciclina D1/ CDK4 o CDK6 y el complejo ciclina E/CDK2 (Foster et al., 2010).

Como se ha descrito, las vías mencionadas tienen, dentro de sus múltiples efectos, acción sobre la

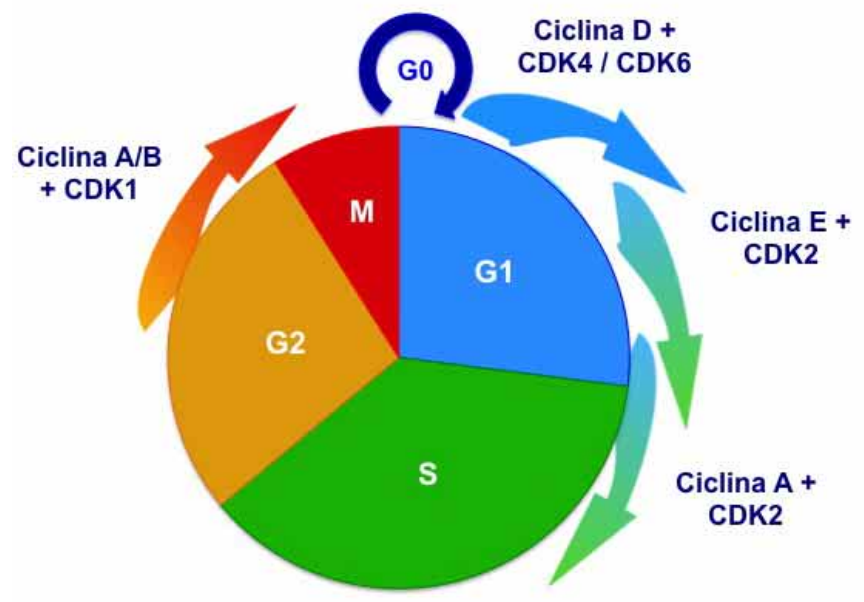

Fig. 4. Complejos Ciclina/CDKs reguladores del ciclo celular. 
expresión de proteínas que estimulan a la célula endotelial a entrar en G1. En el diagrama siguiente se aprecia cómo las vías Ras y mTor participan directa- mente en la expresión de ciclinas $\mathrm{D}$ y $\mathrm{E}$, responsables de la entrada de la célula a división (Fig. 5).

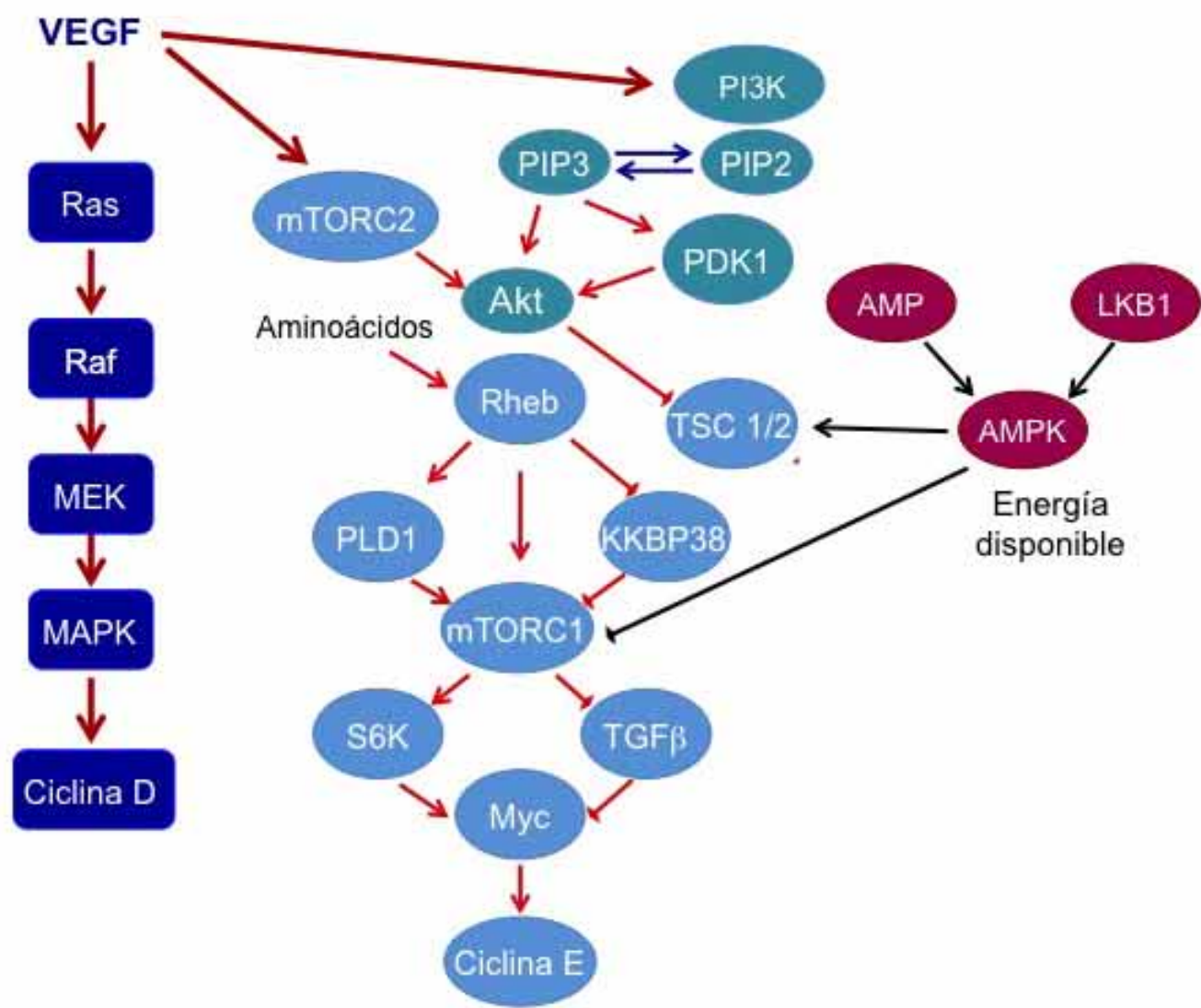

Fig. 5. Vías Ras y PI3K activadas por el VEGF conducentes a la expresión de ciclinas reguladoras del ciclo celular.

\section{CONCLUSIONES}

El desarrollo de la medicina regenerativa y la ingeniería tisular ha sido enorme en las últimas décadas, logrando posicionar técnicas y biomateriales en el quehacer cotidiano de la periodoncia, Implantología y cirugía bucal. EI L-PRF no es la excepción y se utiliza para diversos procedimientos tendientes a "mejorar la cicatrización". En el presente manuscrito se aborda este tema con una mirada menos clínica y más biológica para ayudar al lector a comprender con un poco más de profundidad el efecto de los factores de crecimiento presentes en las plaquetas a nivel del ciclo celular de las células que participan de este proceso reparativo. Se enfocó principalmente el rol del VEGF como actor principal, pero es necesario mantener presente que el proceso inflamatorio reparativo es un conjunto orquestado de muchísimos mas elementos cuyos efectos confluyen a la resolución de la lesión inicial.
CORREA, A. J.; ALISTER, J. P.; OLATE, S. \& MANTEROLA, C. L-PRF and cell cycle. A narrative review. Int. J. Odontostomat., 13(4):497-503, 2019

ABSTRACT: Platelet concentrates (PC) have emerged as a potential regenerative material, used in isolation or as scaffolding for other graft materials. They are blood extracts, obtained after processing a sample of whole blood, by centrifugation. The first report dates from 1970, with a PC used glue to improve the healing of skin wounds. In 1998, they were used in oral and maxillofacial surgery. Since then, different techniques and a variety of preparations have been developed. These include platelet-rich plasma, fibrin rich in platelets and leukocytes (L-PRF) and plasma rich in growth factors (PRGF). The development of these biomaterials, is due in part to the possibility of altering the concentration of chemical mediators released in a lesion that causes the formation of a clot, which can mature as the 
phases of the inflammatory process pass and conclude with the complete regeneration of the damaged tissue. The aim of this manuscript was to describe the main intracellular signaling pathways that are activated in the presence of LPRF in oral surgery, and its effects on the regulation of the cell cycle.

KEY WORDS: "Growth Differentiation Factors"[Mesh]; "Receptors, Cytokine"[Mesh]; "Angiogenesis Modulating Agents"[Mesh]; "Periodontics"[Mesh]; "Regenerative Endodontics "[Mesh]; "Platelet-Rich Fibrin"[Mesh]; "Regenerative Medicine"[Mesh].

\section{REFERENCIAS BIBLIOGRÁFICAS}

Aguirre Siancas, E. E. Influencia de la hipoxia sobre el metabolismo óseo. Rol central del factor inducible por hipoxi. An. Fac. Med., 74(4):321-5, 2013.

Castro, A. B.; Cortellini, S.; Temmerman, A.; Li, X.; Pinto, N.; Teughels, W. \& Quirynen, M. Characterization of the leukocyte- and plateletrich fibrin block: release of growth factors, cellular content, and structure. Int. J. Oral Maxillofac. Implants, 34(4):855-64, 2019.

Castro, A. B.; Meschi, N.; Temmerman, A.; Pinto, N.; Lambrechts, P.; Teughels, W. \& Quirynen, M. Regenerative potential of leucocyte- and platelet-rich fibrin. Part B: sinus floor elevation, alveolar ridge preservation and implant therapy. A systematic review. J. Clin. Periodontol., 44(2):225-34, 2017a.

Castro, A. B.; Meschi, N.; Temmerman, A.; Pinto, N.; Lambrechts, P.; Teughels, W. \& Quirynen, M. Regenerative potential of leucocyte- and platelet-rich fibrin. Part A: intra-bony defects, furcation defects and periodontal plastic surgery. A systematic review and meta-analysis. J. Clin. Periodontol., 44(1):67-82, 2017b.

Chang, F.; Steelman, L. S.; Lee, J. T.; Shelton, J. G.; Navolanic, P. M.; Blalock, W. L.; Franklin, R. A. \& McCubrey, J. A. Signal transduction mediated by the Ras/Raf/MEK/ERK pathway from cytokine receptors to transcription factors: potential targeting for therapeutic intervention. Leukemia, 17(7):1263-93, 2003.

Choukroun, J.; Adda, F.; Schoeffler, C. \& Vervelle, A Une opportunité en paro-implantologie: le PRF. Implantodontie, 42;55-62, 2001.

Foster, D. A.; Yellen, P.; Xu, L. \& Saqcena, M. Regulation of G1 cell cycle progression: distinguishing the restriction point from a nutrient-sensing cell growth checkpoint(s). Genes Cancer, 1(11):1124-31, 2010.

Gan, X.; Wang, J.; Su, B. \& Wu, D.. Evidence for direct activation of mTORC2 kinase activity by phosphatidylinositol 3,4,5trisphosphate. J. Biol. Chem., 286(13):10998-1002, 2011.

Guo, D.; Murdoch, C. E.; Liu, T.; Qu, J.; Jiao, S.; Wang, Y.; Wang, W. \& Chen, $X$. Therapeutic angiogenesis of Chinese herbal medicines in ischemic heart disease: a review. Front. Pharmacol., 9:428, 2018.

Hotwani, K. \& Sharma, K. Platelet rich fibrin - a novel acumen into regenerative endodontic therapy. Restor. Dent. Endod., 39(1):16, 2014.

Karar, J. \& Maity, A. PI3K/AKT/mTOR pathway in angiogenesis. Front. Mol. Neurosci., 4:51, 2011.

Kobayashi, E.; Flückiger, L.; Fujioka-Kobayashi, M.; Sawada, K.; Sculean, A.; Schaller, B. \& Miron, R. J. Comparative release of growth factors from PRP, PRF, and advanced-PRF. Clin. Oral Investig., 20(9):2353-60, 2016.
Mammoto, T.; Jiang, A.; Jiang, E. \& Mammoto, A. Platelet rich plasma extract promotes angiogenesis through the angiopoietin1Tie2 pathway. Microvasc. Res., 89:15-24, 2013.

Martínez, C. E.; Smith, P. C. \& Palma Alvarado, V. A. The influence of platelet-derived products on angiogenesis and tissue repair: a concise update. Front. Physiol., 6:290, 2015.

Matsumoto, T. \& Claesson-Welsh, L. VEGF receptor signal transduction. Sci. STKE, 2001(112):re21, 2001.

Pinto, N. R.; Ubilla, M.; Zamora, Y.; Del Rio, V.; Dohan Ehrenfest, D. M. \& Quirynen, M. Leucocyte- and platelet-rich fibrin (L-PRF) as a regenerative medicine strategy for the treatment of refractory leg ulcers: a prospective cohort study. Platelets, 29(5):468-75, 2018.

Pinto, N.; Harnish, A.; Cabrera, C.; Andrade, C.; Druttman, T. \& Brizuela, C. An innovative regenerative endodontic procedure using leukocyte and platelet-rich fibrin associated with apical surgery: a case report. J. Endod., 43(11):1828-34, 2017.

Pinzón, C. E.; Serrano, M. L. \& Sanabria, M. C. Papel de la vía fosfatidilinositol 3 kinasa (PI3K/Akt) en humanos. Rev. Cienc. Salud Bogotá, 7(2):47-66, 2009.

Saavedra Torres, J. S.; Zúñiga Cerón, L. F.; Freyre Bernal, S. I.; Muñoz Ordoñez, G. W. \& Salguero, C. El rol de VEGF en la Angiogénesis fisiológica y tumoral. Rev. Med., 39(3):190-209, 2017.

Susin, C. \& Wikesjö, U. M. Regenerative periodontal therapy: 30 years of lessons learned and unlearned. Periodontol. 2000, 62(1):232-42, 2013.

Dirección para correspondencia:

Dr. Carlos Manterola

CEMyQ

Universidad de La Frontera,

Temuco

CHILE

Email: carlos.manterola@ufrontera.cl

Recibido : 14-05-2019

Aceptado: 26-06-2019 